\title{
Audit of Gross Decay Treatment in Young Children under General Anaesthetic
}

\author{
Jacqueline A. Pawlak ${ }^{1}$, Hanny Calache ${ }^{2,4}$, Andrea M. de Silva ${ }^{2,3}$, Margaret J. Henry ${ }^{1}$ and Michael Smith ${ }^{1 *}$ \\ ${ }^{1}$ Barwon Health Oral Health Service, 104-108 Bellarine Highway, Newcomb, 3219, Victoria, Australia \\ ${ }^{2}$ Dental Health Services Victoria, 720 Swanston Street, Carlton 3053, Victoria, Australia \\ ${ }^{3}$ Melbourne Dental School University of Melbourne, 720 Swanston Street, Carlton 3053, Victoria Australia \\ ${ }^{4}$ La Trobe Rural Health School, Dentistry and Oral Health, College of Science, Health and Engineering, La Trobe University, P.O. Box 199, Bendigo, 3552, Victoria, \\ Australia
}

\begin{abstract}
In Australia, dental caries is one of the most prevalent diseases effecting children. For more severe cases a dental general anaesthetic (GA) is required. A retrospective analysis of clinical records for all patients aged up to 10 years who attended Barwon Health (Geelong, Victoria, Australia) for a dental GA from 2010-2012 was performed. There were 236 separate events in 234 children, with 223 new cases and 11 that had already received a dental GA prior to the study period. The average age of patients at their dental GA procedure was $6.3 \pm 2.0$ years. Prior to the GA, the average dmft/ DMFT was 8 (6-12) (median, interquartile range). The length of time from referral to GA increased significantly from 166.4 days (SD 108.1), 164.3 days (SD 98.9) to225.4 days (SD 129.5) in 2010, 2011 and 2012, respectively. Follow up review appointments after GA appointment was attended by $10.8 \%, 37.3 \%$ and $36.0 \%$ of patients, respectively across the same years. Following the findings of long waiting times for GA procedures for children with severe dental caries, and the low rate of attendance for post-GA reviews, a change in dental process is urgently needed.
\end{abstract}

Keywords: Anaesthesia; Caries; Caries treatment; Dental hygiene; Dental public health; Pediatric dentistry

Abbreviations: Dmft: decayed, missing or filled teeth- (deciduous/ primary dentition); DMFT: Decayed, Missing or Filled Teeth (permanent/secondary dentition); GA: General Anesthesia; IQR: Interquartile Range; SD: Standard Deviation

\section{Introduction}

In Australia, dental caries (decay) is one of the most prevalent diseases effecting children [1]. A report by the Australian Institute of Health and Welfare stated that "among children aged 5-6 y old, nearly half (48.7\%) had a history of tooth decay in the deciduous teeth" [2]. Dental disease in childhood is a serious condition resulting in acute pain, problems with eating, sleep deprivation and decreased selfesteem. Severe dental caries in children also has an impact on those who care for the child and share the household [3].

Poor diet and nutrition impact oral health, resulting in not only local damage to the teeth but also a systemic effect on the integrity of the teeth. Studies have reported that in children from more disadvantaged areas, caries often co-exists with obesity [4]. The number of missing, decayed or filled teeth in children from the lowest socio-economic areas has been reported to be as much as $70 \%$ higher than those from the highest socio-economic areas [2]. Sanders in 2007 [5] reported that adults from a disadvantaged background during childhood experienced greater tooth loss in adulthood.

The total expenditure for dental services in 2009-2010 within Australia was $\$ 7,690$ million [6]. Ideally, timely prevention of tooth decay would not only ease the pain for the child but also reduce the economic burden. Premature loss of deciduous teeth may result in a decrease in space for the permanent teeth, leading to the development of crowding and the need for possible orthodontic intervention furthering pain and financial burden.

While some children receive treatment in a dental chair, for more severe cases, medical complications or child behavioural problems a dental general anaesthetic (GA) may be required. Dental GA procedures in the hospital utilise intensive resources and can present with side-effects or complications [7]. Within Australia, child dental GA rates are increasing alarmingly with a three-fold rise in rates over a decade (1993-1994) compared to (2003-2004) [8]. Few recent studies (2010-2012) have investigated patterns of dental GA utilisation within Australia.

Our catchment area within Victoria, Australia contains the following local government areas: the City of Greater Geelong, SurfCoast Shire and the Golden Plains Shire (South). Within the region, the major city is Geelong, and is the second largest city within the state of Victoria. In addition to Geelong, the City of Greater Geelong includes small townships, coastal resort towns, small acreage properties and larger farms (population 210,875 area $1,248 \mathrm{~km}^{2}$ ). The Surf Coast Shire includes mainly coastal areas (population 25,870 area 1,553 $\mathrm{km}^{2}$ ). The Golden Plains Shire (south) (population 18,770 area 2,703 $\mathrm{km}^{2}$ ) consists of smaller townships and farming regions. There were 38,100 (14\%) children aged less than 10 years old in 2011 [9] and is a similar proportion to that of the broader Australian population. The only public oral health service is managed by Barwon Health and has multiple community health centres throughout the area

Having an understanding of the dental care profile of children and adolescents presenting for dental treatment under GA will enable the development and implementation of preventive interventions that aim to reduce the rate of GA's among children and adolescents in the Barwon region and reduce the economic burden on society associated with dental treatment under GA. The research question explored in

${ }^{*}$ Corresponding author: Dr. Michael Smith, Barwon Health Oral Health Service, 104-108 Bellarine Highway, Newcomb, 3219, Australia, Tel: +61 342153330 E-mail: michae@barwonhealth.org.au

Received April 16, 2015; Accepted May 05, 2015; Published May 06, 2015

Citation: Pawlak JA, Calache H, de Silva AM, Henry MJ, Smith M (2015) Audit of Gross Decay Treatment in Young Children under General Anaesthetic. Dentistry 5 302. doi:10.4172/2161-1122.1000302

Copyright: ( 2015 Pawlak JA, et al. This is an open-access article distributed under the terms of the Creative Commons Attribution License, which permits unrestricted use, distribution, and reproduction in any medium, provided the original author and source are credited. 
this study is 'What is the dental care profile of children and adolescents receiving dental treatment under general anaesthetic in the Barwon geographical region of Victoria, Australia?

\section{Materials and Methods}

\section{Ethics}

Ethical approval for this retrospective data audit was obtained from the Barwon Health Human Research Ethics Committee (reference number 12/75).

\section{Data collection}

All dental GA procedures are performed at the one site, the Gretta Volum Centre, Barwon Health. All GA dental records from 2010 to 2012, were reviewed (Figure 1). Data was extracted from the titanium information management system (Version 14) that is a public oral health patient management system used within Australia. This database includes information on courses of care, gender, date of birth, initial presentation date, appointment prior to GA, treatment date, follow up appointment post GA, length of waiting time and treatment provided. In addition, codes for description of treatment in accordance with 'The Australian Schedule of Dental Services and Glossary' (2013) were recorded [10]. Patient inclusion criteria was those aged less than 10 years at time of initial consultation and resided within the local Government areas of Greater Geelong, Surf Coast or Golden Plains (South) areas of Victoria, Australia. Data was stored electronically by the Oral Health Services Department, Barwon Health, which was password protected.

\section{Data handling and analysis}

Summary statistics were generated to determine the profile for the area. A measure of dental disease severity (prior to GA) was calculated by clinicians based on the number of decayed, missing or filled teeth (dmft/DMFT). A mixture of dentition (dmft/DMFT) is observed as from approximately 6 years of age children begin losing their primary teeth which are replaced by permanent teeth. By age 12 approximately all primary teeth are replaced by permanent teeth. The date of referral for GA appointments was recorded in Titanium. GA incidence was calculated with the number of children receiving dental GA as the numerator and the number of a similar age presenting to the Oral Health services at Barwon Health as the denominator. Waiting times were compared using Analysis of Variance and Tukeys test applied.

\section{Results}

There were 236 events under GA. Eleven of these children had already received a dental GA prior to the study period while 223 were new cases. Nineteen of these events were children presenting with special needs. The incidence of children who present to dental health services receiving a dental GA was 15.3, 11.4 and 14.4 per 1,000 person years for 2010 to 2012, respectively. The incidence of children within the region receiving a dental GA was $2.2,1.8$ and 2.3 per 1,000 person years, respectively. Average age at initial consultation was $5.5 \pm 2.1$ years (mean $\pm \mathrm{SD}$ ). The average age when patients were referred for GA was $5.8 \pm 2.0$ years and for their attendance for GA procedure was $6.3 \pm 2.0$ years. In total, 83 were treated in 2010, 67 in 2011 and $86 \mathrm{in}$ 2012 with $64 \%, 46 \%$ and $52 \%$ male.

The length of time from referral to attendance for GA procedure was significantly increased in $2012(\mathrm{p}<0.01)$ (Table 1). A follow-up appointment post GA review was attended by $10.8 \%, 37.3 \%$ and $36.0 \%$ of patients in 2010, 2011 and 2012 respectively (Table 1). Prior to the
GA, the average number of decayed, missing or filled teeth $(\mathrm{dmft} /$ DMFT) was 8 (6-12) (median, interquartile range - IQR).

Treatment primarily included removal of teeth and on average 4 (2-6) (median IQR), teeth were extracted, with 2 children having 20

\section{Flow Chart}

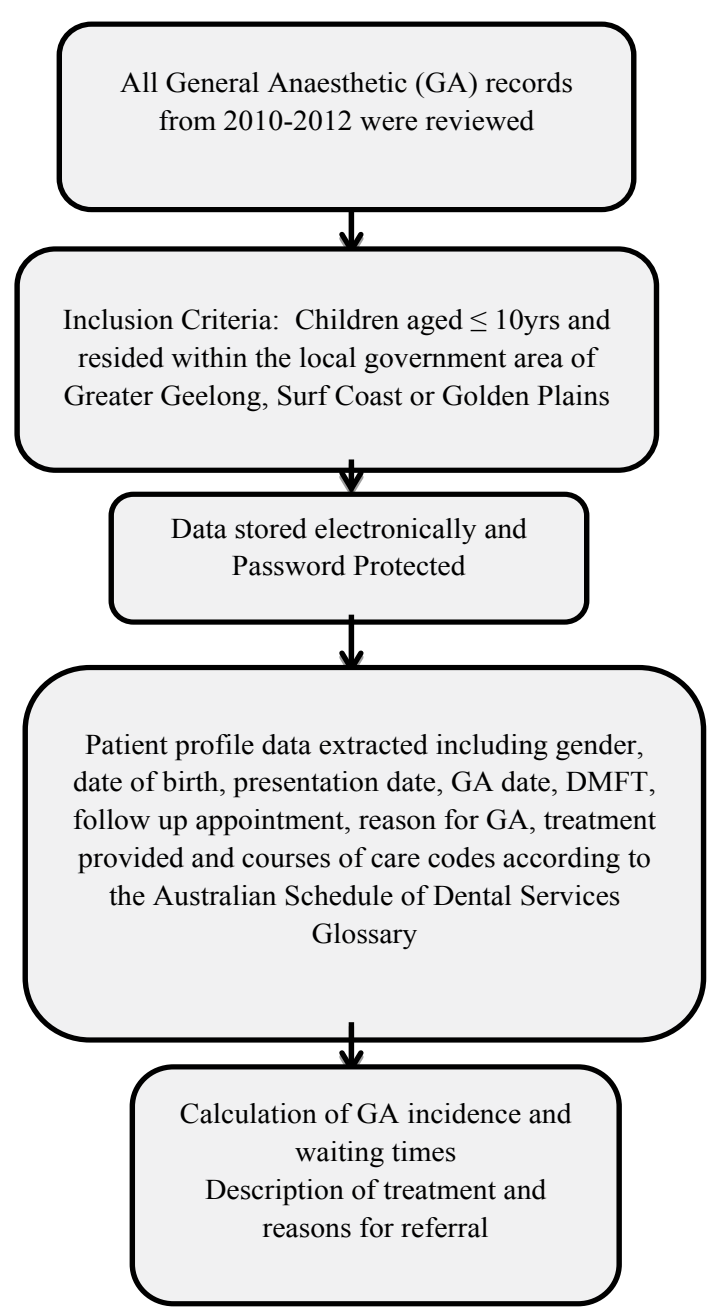

Figure 1: All GA dental records from 2010 to 2012.

\begin{tabular}{|c|c|c|c|c|}
\hline & $\begin{array}{c}2010 \\
(n=83)\end{array}$ & $\begin{array}{c}2011 \\
(n=67)\end{array}$ & $\begin{array}{c}2012 \\
(n=86)\end{array}$ & $p$ value \\
\hline $\begin{array}{l}\text { Attendedappointment } \\
\text { prior to GA } \\
\text { number }(\%)\end{array}$ & $44(53.0)$ & $38(56.7)$ & $43(50.0)$ & 0.71 \\
\hline $\begin{array}{l}\text { Length of time from } \\
\text { referral to GA } \\
\text { (days; mean } \pm S D)\end{array}$ & $166.4 \pm 108.1$ & $164.3 \pm 98.9$ & "225.4 \pm 129.5 & 0.01 \\
\hline $\begin{array}{l}\text { Attended follow-up } \\
\text { appointment post-GA } \\
\text { number }(\%)\end{array}$ & $9(10.8)$ & $25(37.3)$ & $31(36.0)$ & 0.00 \\
\hline $\begin{array}{l}\text { dmft/DMFTprior to GA } \\
\text { median (IQR) }\end{array}$ & $9(6-11)$ & $9(6-13)$ & $7(4-11)$ & 0.09 \\
\hline
\end{tabular}

Table 1: GA treatments for dental procedures between 2010-2012 at Barwon Health. 
teeth extracted, and 13(5.5\%) having more than 10 teeth extracted. At least one tooth was removed for $220(93.2 \%)$ of the children. Restoration of the teeth occurred on at least 1surface for $180(76.3 \%)$ patients. An average of 2 (1-4) (median IQR) teeth were filled with 30(12.7\%) children having more than 5 teeth restored (Table 2). While attending their GA dental visit $65(27.5 \%)$ patients received a comprehensive oral examination. Seventeen (7.2\%) received preventive treatments of fissure and/or tooth surface sealing (Table 2).

\section{Discussion}

This study reports long waiting times (5 to 7 months) for GA procedures for children whose average age is just over 6 years at the time of the GA procedure. A study from New South Wales, Australia in 1996 reported waiting times of between 2 and 3 months [11]. Consequences of long waiting times include children requiring analgesics, sleep disturbances, eating problems and further deterioration of the dentition requiring more extensive treatment and possibly loss of teeth that could have otherwise have been restored and saved [12]. The level of dental disease observed in the children would affect their ability to perform at school, day care or in social situations and also have a ripple effect on the rest of family.

Twenty of the children in our study received multiple dental GAs ranging between 2006 and 2014 (19 children received two dental GAs while one child received three). The Geelong region water supply was fluoridated in June 2009. Many children involved in this study have not benefitted from life-long exposure to water fluoridation. This may be one of the attributing factors to the high treatment needs of this population group in the Geelong region. Dental Health Services Victoria have recently amended their Clinical Guidelines with recommendations aimed at minimising the need for repeat general anaesthetics for dental care in children following similar trends in repeat GA's at Royal Dental Hospital Melbourne (between October 2003 and September 2008; DHSV, 2014). The current guidelines recommend the use of stainless steel crowns as the restoration of choice for restorations in children with a high incidence of caries [13]. No stainless steel crowns were inserted in this study group. In 2013 the Oral Health Services Department of Barwon Health began utilising the Hall technique [14] of placing stainless steel crowns in children to improve patient care at an early stage to reduce the risk of gross decay in children. The Hall technique avoids the use of local anaesthetics and rotary instruments for tooth preparation.

Considering the length of time from initial consultation and referral to the GA session all patients would be expected to attend a pre-GA dental appointment. In this appointment dental needs would be reassessed and the medical history updated. Unfortunately, in the present study, in 2012 preliminary dental appointments were attended by only $50 \%$ of patients and this hadn't really changed from 2010 . The General Anaesthetic Guideline advises that, following the initial consultation, children and their parents/carers should be engaged to discuss the reasons for the child experiencing dental disease and the strategies to be put in place to remineralize early lesions and improve oral health. This could involve motivational interviewing, tooth brushing techniques, the appropriate use of fluoride toothpaste and managing contributing factors i.e. diet and drink choices. There was limited evidence of such interventions happening even for the children who did attend the preGA appointment, as "Oral Hygiene Instruction" was given to only 12 , 27 and 9 children in 2010, 2011 and 2012 respectively.

In the present study, post GA reviews were attended by only a small proportion of children, increasing from $11 \%$ in 2010 to close

\begin{tabular}{|c|c|c|c|}
\hline Description of Treatment & $\begin{array}{c}\text { \# Treatments Performed } \\
2010\end{array}$ & $\begin{array}{l}\text { \# Treatments Performed } \\
2011\end{array}$ & $\begin{array}{c}\text { \# Treatments Performed } \\
2012\end{array}$ \\
\hline Comprehensive oral examination & 14 & 25 & 26 \\
\hline Removal of plaque and/or stain & 1 & 0 & 1 \\
\hline Removal of calculus - first visit & 0 & 2 & 1 \\
\hline Oral hygiene instructions & 12 & 27 & 9 \\
\hline Removal of tooth or part(s) thereof & $\begin{array}{l}\text { Events }=77 \\
\text { Teeth }=404\end{array}$ & $\begin{array}{l}\text { Events }=64 \\
\text { Teeth }=336\end{array}$ & $\begin{array}{l}\text { Events }=79 \\
\text { Teeth }=335\end{array}$ \\
\hline Fissure and/or tooth surface sealing - per tooth & $\begin{array}{l}\text { Events }=9 \\
\text { Teeth }=14\end{array}$ & $\begin{array}{l}\text { Events }=3 \\
\text { Teeth }=5\end{array}$ & $\begin{array}{l}\text { Events }=5 \\
\text { Teeth }=18\end{array}$ \\
\hline Adhesive restoration - one surface - anterior tooth - direct & $\begin{array}{c}\text { Events }=17 \\
\text { Teeth }=30\end{array}$ & $\begin{array}{l}\text { Events }=4 \\
\text { Teeth }=10\end{array}$ & $\begin{array}{l}\text { Events }=12 \\
\text { Teeth }=18\end{array}$ \\
\hline Adhesive restoration - two surfaces - anterior tooth - direct & $\begin{array}{l}\text { Events }=7 \\
\text { Teeth }=9\end{array}$ & $\begin{array}{l}\text { Events }=5 \\
\text { Teeth }=7\end{array}$ & $\begin{array}{l}\text { Events }=10 \\
\text { Teeth }=20\end{array}$ \\
\hline Adhesive restoration - three surfaces - anterior tooth- direct & $\begin{array}{l}\text { Events }=3 \\
\text { Teeth }=7\end{array}$ & $\begin{array}{c}\text { Events }=1 \\
\text { Teeth }=2\end{array}$ & $\begin{array}{l}\text { Events }=1 \\
\text { Teeth }=2\end{array}$ \\
\hline Adhesive restoration - four surfaces - anterior tooth - direct & 0 & 0 & 0 \\
\hline Adhesive restoration - one surface - posterior tooth - direct - composite & $\begin{array}{c}\text { Events }=27 \\
\text { Teeth }=78\end{array}$ & $\begin{array}{c}\text { Events }=22 \\
\text { Teeth }=51\end{array}$ & $\begin{array}{l}\text { Events }=39 \\
\text { Teeth }=101\end{array}$ \\
\hline GIC - one surface - posterior tooth & $\begin{array}{c}\text { Events }=23 \\
\text { Teeth }=54\end{array}$ & $\begin{array}{c}\text { Events }=11 \\
\text { Teeth }=44\end{array}$ & $\begin{array}{c}\text { Events }=10 \\
\text { Teeth }=22\end{array}$ \\
\hline Adhesive restoration - two surfaces - posterior tooth - direct & $\begin{array}{l}\text { Events }=15 \\
\text { Teeth }=20\end{array}$ & $\begin{array}{c}\text { Events }=17 \\
\text { Teeth }=30\end{array}$ & $\begin{array}{c}\text { Events }=13 \\
\text { Teeth }=23\end{array}$ \\
\hline GIC - two surfaces - posterior tooth & $\begin{array}{c}\text { Events }=16 \\
\text { Teeth }=24\end{array}$ & $\begin{array}{l}\text { Events }=9 \\
\text { Teeth }=17\end{array}$ & $\begin{array}{l}\text { Events }=7 \\
\text { Teeth }=11\end{array}$ \\
\hline Adhesive restoration - three surfaces - posterior tooth - direct & 0 & 0 & 1 \\
\hline GIC - three surfaces - posterior tooth & 0 & 2 & 2 \\
\hline Metallic restoration - one surface -direct & 4 & 0 & 0 \\
\hline Metallic restoration - two surfaces - direct & 0 & 0 & 0 \\
\hline Recontouring and polishing of pre-existing restoration(s) & 1 & 0 & 0 \\
\hline
\end{tabular}

Table 2: Treatments performed under dental GA at Barwon Health by year. 
Citation: Pawlak JA, Calache H, de Silva AM, Henry MJ, Smith M (2015) Audit of Gross Decay Treatment in Young Children under General Anaesthetic. Dentistry 5: 302. doi:10.4172/2161-1122.1000302

to $40 \%$ in 2012 . The increase could be attributed to the introduction of Minimal Intervention Dentistry and associated professional development program to support changed clinical practice. A followup dental appointment is beneficial to review restorations, behaviour modification, to reinforce oral health messages and to promote prevention. Failure to attend follow-up appointments might also be a risk factor for multiple GAs. Additional data available (unpublished) shows that the dental recall rates for children attending Barwon Health dental clinics, at risk of dental caries over 2011-2012 was about $65 \%$. It appears that the children receiving dental treatment under GA are less likely to return for a follow-up appointment compared to other dental treatment. Variable post dental GA review rates have been reported overseas. Between 1998 and 2002 at the University of Iowa Hospitals and Clinic, USA $54 \%$ of patients returned for a 2 week post GA visit [15]. A study conducted in Buffalo, USA in 2000 reported low rates (39\%) of children returning for their immediate follow-up appointment [16]. A recent study in Saudi Arabia reported lower percentages (14\%) of patients complying fully with the post-operative recall schedule [17]. Factors contributing to GA review rates are likely to include: cultural [17], socio-demographic, socio-economic and some patients may perceive the appointment as being unnecessary if they have not experienced any adverse effects from the dental GA treatment.

An increase in children's dental GA rates across Australia has been observed over the mid 1980's to 1996 [11]. In this study, approximately one child in 500 in the region were presenting for dental treatment under GA. The use of GAs within public hospitals has increased over the last few years [18]. The reasons for these increases prompted this study to be undertaken. We report no increase in dental GA rates from 2010 to 2012 in the Barwon South-Western region. However, the number of dental GA sessions available through the public health system locally have been utilised to their capacity. In the short-term the treatment of children with severe dental caries under GA results in immediate oralhealth-related quality-of-life enhancements for the child and family [3]. Prevention and behaviour modification approaches are essential to ensure sustainability of dental health.

A limitation of the study is that this is a cross-sectional observational retrospective study over the years 2010-2012. This early data however gives a clear view of the size of the problem within the region. Post 2012, there has been substantial changes within the Oral Health Services Department at Barwon Health in an effort to improve patient care with the introduction of professional development programs to encourage the placement of conventional stainless steel crowns under GA by clinicians, the introduction of the Hall technique for placing stainless steel crowns in the dental chair (i.e. not under GA) and the introduction of Minimal Intervention Dentistry (MID techniques, preventative measures). Future research projects will test whether these interventions have been successful in reducing the number of new and repeat GAs in the region. In conclusion, the results of this study demonstrate alarmingly high waiting times between dental GA referrals and procedures for children as young as 6 yrs old, coupled with high dental-GA rates along with low attendance at post GA review.

\section{Acknowledgments}

We would like to sincerely thank Dentist Dr Sonia Barreto Orozco who assisted with collating the data. This research received no specific grant from any funding agency in the public, commercial, or not-for-profit sectors. The authors declare no potential conflict of interest with respect to the authorship and/or publication of this article.

\section{References}

1. Rogers JG (2011) Evidence-based Oral Health Promotion Resource. Prevention and Population Health Branch, Government of Victoria, Department of Health, Melbourne, Victoria, Australia.

2. AlHW (2011) Australian Institute of Health and Welfare. Dental decay among Australian children. Series Number 53. Cat. no.DEN 210. Canberra, Australia.

3. Thomson WM, Malden PE (2011) Assessing change in the family impact of caries in young children after treatment under general anaesthesia. Acta Odontol Scand 69: 257-262.

4. Marshall TA, Eichenberger-Gilmore JM, Broffitt BA, Warren JJ, Levy SM (2007) Dental caries and childhood obesity: roles of diet and socioeconomic status. Community Dent Oral Epidemiol 35: 449-458.

5. Sanders A (2007) Social determinants of oral health: conditions linked to socioeconomic inequalities in oral health and in the Australian population. Population Oral Health Series No. 7. Australian Institute of Health and Welfare, Canberra, Australia.

6. Chrisopolous S, Beckwith K, Harford J (2011)Oral health and dental care in Australia - key facts and figures 2011. Cat no. DEN 214. Australian Institute of Health and Welfare, Canberra, Australia.

7. Verco S, Bajurnow A, Grubor D, Chandu A (2011) A five-year assessment of clinical incidents requiring transfer in a dental hospital day surgery unit. Aust Dent J 56: 412-416.

8. Jamieson LM1, Roberts-Thomson KF (2006) Dental general anaesthetic trends among Australian children. BMC Oral Health 6: 16.

9. ABS (2011) The Australian Bureau of Statistics Census QuickStats: [accessed 2014 Nov 12]

10. The Australian Schedule of Dental Services and Glossary (2013) Australian Dental Association Incorporation. Tenth Edition: 1-88.

11. Alcaino E, Kilpatrick NM, Smith ED (2000) Utilization of day stay general anaesthesia for the provision of dental treatment to children in New South Wales, Australia. Int J Paediatr Dent 10: 206-212.

12. North S, Davidson LE, Blinkhorn AS, Mackie IC (2007) The effects of a long wait for children's dental general anaesthesia. Int J Paediatr Dent 17: 105-109.

13. DHSV (2014) Dental Health Services Victoria. Treatment planning for children managed under dental general anaesthesia. Clinical Guideline 18 - Version 2 Valid to March 2017. Melbourne (Australia).

14. Innes NP, Evans DJP, Stirrups DR (2007) The Hall Technique: a randomized controlled clinical trial of a novel method of managing carious primary molars in general dental practice: acceptability of the technique and outcomes at 23 months. BMC Oral Health 7: 18

15. Jamieson WJ, Vargas K (2007) Recall rates and caries experience of patients undergoing general anesthesia for dental treatment. Pediatr Dent 29: 253-257.

16. Foster T, Perinpanayagam H, Pfaffenbach A, Certo M (2006) Recurrence of early childhood caries after comprehensive treatment with general anesthesia and follow-up. J Dent Child (Chic) 73: 25-30.

17. El Batawi HY (2014) Factors affecting clinical outcome following treatment of early childhood caries under general anaesthesia: a two-year follow-up. Eur Arch Paediatr Dent 15: 183-189.

18. Madan C, Kruger E, Perera I, Tennant M (2010) Trends in demand for general anaesthetic care for paediatric caries in Western Australia: geographic and socio-economic modelling of service utilisation. Int Dent J 60: 190-196. 